\title{
Fosfito de potássio ameniza os sintomas de Fusarium oxysporum em bananeiras
}

\author{
Lincoln Graia do Nascimento Cunha', Leandra Regina Semensato ${ }^{2}$, Eduardo Pradi Vendruscolo ${ }^{3}$ e \\ Míriam de Almeida Marques²
}

\begin{abstract}
Resumo - O objetivo deste trabalho foi avaliar a ação do fosfito de potássio sobre os sintomas do mal do panamá. Para tanto, quatro doses de fosfito de potássio $\left(5 ; 10 ; 15 ; 20 \mathrm{~mL} \mathrm{planta-1}^{-1}\right)$ e um tratamento controle foram utilizados. Foram avaliadas a severidade dos sintomas e a produtividade por planta de bananeiras "Prata Anã". Verificou-se que houve evolução da doença no decorrer dos meses de avaliação nas plantas do tratamento controle, chegando a um máximo de $95 \%$ de infecção no mês de abril, o que causou perda total da produção. Para a severidade dos sintomas, obteve-se uma redução média nos meses de $46,79 \%$ quando aplicada a dose de $10 \mathrm{~mL}_{\text {planta }}{ }^{-1}$, enquanto que para a produtividade foi calculada uma dose máxima de $14,43 \mathrm{~mL}_{\text {planta }}{ }^{-1}$, para a qual foi constatada produtividade de $18,97 \mathrm{~kg}$ planta-1. Assim, concluiu-se que doses de fosfito de potássio situadas entre 10 e $15 \mathrm{ml}$ planta-1 ${ }^{-1}$, reduzem significativamente a severidade dos sintomas do mal do panamá em bananeiras, incrementando sua produtividade em área contaminada.
\end{abstract}

Termos para indexação: Controle alternativo; mal do panamá; Musa sp.

\section{Potassium phosphite alleviate the symptoms of Fusarium oxysporum in banana trees}

Abstract - The objective of this work was to evaluate the potassium phosphite action, in different doses, on the effects of Panama disease. For this purpose, five doses of potassium phosphite $\left(5 ; 10 ; 15 ; 20 \mathrm{~mL} \mathrm{plant}^{-1}\right)$ and a control treatment were used. Symptom severity and productivity per "Prata Anã" banana plant were evaluated. It was found that there was an evolution of the disease during the months of evaluation in the plants of the control treatment, reaching a maximum of $95 \%$ of infection in the month of April, causing total loss of production. For the severity of symptoms, an average reduction in months of $46.79 \%$ was obtained when the dose of $10 \mathrm{~mL}^{\text {plant }}{ }^{-1}$ was applied, while for productivity a maximum dose of $14.43 \mathrm{~mL} \mathrm{plant}^{-1}$ was calculated, for yield of $18.97 \mathrm{~kg} \mathrm{plant}^{-1}$ was found. Thus, it was concluded that doses of potassium phosphite, between 10 and $15 \mathrm{ml} \mathrm{plant}^{-1}$, significantly reduce the severity of the symptoms of Panama disease in banana trees, increasing their productivity in a contaminated area.

Index terms: Alternative control; Panama disease; Musa sp.

A banana é um dos principais frutos comercializados e compõe parte importante da dieta de diferentes comunidades ao redor do globo. Constando como fonte de energia e nutrientes, a produção mundial do fruto está em torno de 116 milhões de toneladas ao ano (FAO, 2020). No Brasil, a bananicultura é desenvolvida em praticamente todo o território, gerando renda pelo emprego de mão de obra e comercialização dos frutos. Com 6,5 milhões de toneladas produzidas anualmente, o país é o 4으 maior produtor mundial (FAO, 2020).
Como grande parte dos cultivos comerciais, a bananicultura é exigente quanto ao manejo fitossanitário para uma adequada produção. Nesse contexto, o mal do panamá (Fusarium oxysporum f.sp. cubense) tem sido frequentemente apontado como uma das principais enfermidades a atingir as bananeiras (RODRIGUES FILHO et al., 2014), causando perdas de até $100 \%$ da produção em casos de materiais vegetais suscetíveis (SILVA et al., 2011).

O principal método de controle do mal do panamá envolve a utilização de cultivares resistentes, observando-se também a crescente adoção de métodos alternativos (ARAÚJO et al., 2018). Entre os vários métodos alternativos de controle fitossanitário, verificouse a eficácia da aplicação de fosfito de potássio na cultura do maracujazeiro infectado com Fusarium solani (ROCHA SOBRINHO et al., 2016), na cultura da batata por Phytophthora infestans (MACHINANDIARENA et al., 2012), entre outros. Deste modo, vislumbra-se o potencial desse composto para a amenização dos efeitos causados pelo mal do pana-

Recebido em 22/1/2020. Aceito para publicação em 29/8/2020.

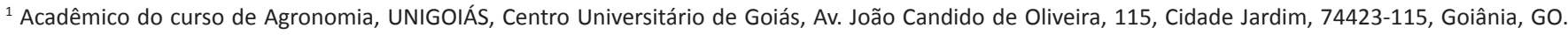
E-mail: lincolnaliancaforte@outlook.com.

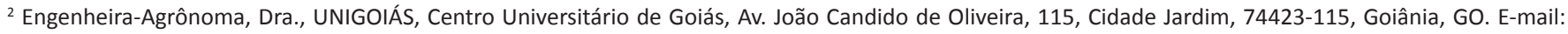
ledocepe@gmail.com, miriamagro@hotmail.com.

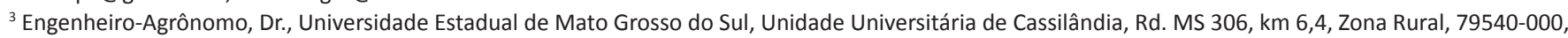
Cassilândia, MS. E-mail: agrovendruscolo@gmail.com. 
má na cultura da bananeira, uma vez que o fosfito de potássio potencializa as respostas de defesa da planta frente à infecção do patógeno e também eleva a velocidade de regeneração dos tecidos acometidos (GENTILE et al., 2009; MACHINANDIARENA et al., 2012).

O fosfito é considerando um fertilizante, que é derivado dos ácidos fosforosos por diferentes bases que podem ser de hidróxido de sódio, amônia e potássio. Esse produto tem como uma das suas principais características a capacidade de estimular a formação de estruturas de autodefesa da planta, pois apresentam efeito fungicida, protegendo-as assim do ataque de fungos (REUVENI, 1997). Portanto, existe a necessidade de estudar os efeitos relacionados ao uso dos fosfitos, para o controle de diferentes espécies de patógenos (CARMONA \& SAUTUA, 2011). Também há a necessidade de se conhecer a dose ideal desses produtos para controle das diferentes doenças, para que o tratamento não venha afetar a produtividade (PERUCH \& BRUNA, 2008). Desta maneira, o objetivo deste trabalho foi avaliar a ação do fosfito de potássio, em diferentes doses, sobre os sintomas do Mal do panamá.

O experimento foi conduzido em propriedade particular, produtora de bananas, localizada no município de Coribe - BA, cujas coordenadas geográficas são latitude $13^{\circ} 37^{\prime} 40,2^{\prime \prime} \mathrm{S}$, longitude $44^{\circ} 21^{\prime} 57,0^{\prime \prime} \mathrm{W}$, com altitude de $505 \mathrm{~m}$ acima do nível do mar, e temperatura média de $23,3^{\circ} \mathrm{C}$ com pluviosidade média anual de $809 \mathrm{~mm}$.

O bananal, onde foi instalado o experimento, foi plantado no ano de 2015, utilizando mudas de banana cv. "Prata Anã”, oriundas de uma área remanescente na propriedade, livre de sintomas e com o espaçamento de 3,0m x 2,0m, totalizando 1.666 plantas ha ${ }^{-1}$. O solo presente na área foi classificado como Latossolo Vermelho-Amarelo, com as seguintes características: M.O. = 1,9\%; $\mathrm{pH}\left(\mathrm{CaCl}_{2}\right)=5,3 ; \mathrm{P}$ (Mehlich) $=13 \mathrm{mg} \mathrm{dm}^{-}$ ; $\mathrm{K}=0,29 \mathrm{cmol}_{\mathrm{c}} \mathrm{dm}^{-3} ; \mathrm{Ca}=6,1 \mathrm{cmol}_{\mathrm{c}} \mathrm{dm}^{-3}$; $\mathrm{Mg}=0,6 \mathrm{cmol}_{\mathrm{c}} \mathrm{dm}^{-3} ; \mathrm{H}+\mathrm{Al}=2,2 \mathrm{cmol}_{\mathrm{c}} \mathrm{dm}^{-}$ 3; $\mathrm{Al}=0,0 \mathrm{cmol}_{\mathrm{c}} \mathrm{dm}^{-3} ; \mathrm{CTC}=9,19 \mathrm{cmol}_{\mathrm{c}}$ $\mathrm{dm}^{-3} ; \mathrm{V} \%=76,06 ; 51,9 \%$ areia, $13,1 \%$ silte e $35 \%$ argila.

A irrigação realizada por sistema de aspersão automatizado, em subcopa, durante uma hora e meia no período da noite, com turnos de rega de 24 horas. Também, durante o período do experimento, foi realizada apenas a adubação orgânica, aplicando-se $5 \mathrm{~kg}$ de esterco de curral curtido por planta, em outubro, coincidindo com o início da época chuvosa na região.

O experimento foi instalado em outubro de 2018, utilizando-se delineamento de blocos casualizados (DBC), com cinco tratamentos e quatro repetições, de duas plantas cada $\left(12 \mathrm{~m}^{2}\right)$. Os tratamentos foram compostos por quatro diferentes dosagens de solução com $5 \mathrm{mg} \mathrm{L}^{-1}$ fosfito de potássio $\left(5 \mathrm{ml}\right.$ planta ${ }^{-1}$, $10 \mathrm{ml}$ planta $^{-1}, 15 \mathrm{ml}$ planta ${ }^{-1}, 20 \mathrm{ml}$ plan$\mathrm{ta}^{-1}$ ) e um tratamento controle, utilizando-se água. As aplicações foram feitas quinzenalmente, no pseudocaule da planta, utilizando uma pistola de fluxo contínuo, com capacidade máxima de 10ml (Höppner, São Paulo, SP, Brasil), mais sonda mamária de $65 \mathrm{~mm}$.

No total foram realizadas 14 aplicações durante os meses de teste, desta maneira o volume total aplicado de solução nos tratamentos foi de 70, 140, 210 e $280 \mathrm{ml} \mathrm{planta}^{-1}$, respectivamente para os tratamentos compostos pelas dosagens de 5, 10, 15 e $20 \mathrm{ml} \mathrm{planta}^{-1}$. As aplicações foram feitas em plantas que se encontravam em sua terceira geração (planta mãe), onde as mesmas entrariam em período de frutificação posteriormente. Para a mistura do produto, foram utilizados $50 \mathrm{ml}$ do fosfito de potássio (Phytogard K, Stoller, Campinas, SP, Brasil) em 10 litros de água.

Para avaliação da severidade do mal do panamá foi utilizada uma escala visual, onde se considerou $0 \%$ de severidade quando a planta não apresentou sintomas da doença e $100 \%$ quando observado o sintoma na totalidade das foIhas das plantas (Tabela 1). Os dados foram coletados mensalmente, a partir do primeiro mês depois da primeira aplicação do fosfito. Ao final do experimento, no momento da colheita, também foi avaliada a produtividade (massa dos cachos) de todas as plantas das parcelas, utilizando-se uma balança de precisão.

Os dados quantitativos, relativos aos tratamentos compostos pelas doses de fosfito de potássio, foram submetidos a análise de regressão, a 5\% de significância. Para a realização das análises foi utilizado o programa computacional SISVAR 5.6 (FERREIRA, 2014).

Observou-se que, independente do mês em que foi realizada a avaliação da severidade dos sintomas de fusário, doses próximas a $10 \mathrm{~mL}$ planta $^{-1}$ foram aquelas que proporcionaram os menores valores de severidade, ou seja,

Tabela 1. Escala para avaliação visual da severidade do mal-do-Panamá em bananeiras Table 1. Scale for visual assessment of the severity of Panama disease in banana trees

\begin{tabular}{cc}
\hline Nota & \multicolumn{1}{c}{ Descrição da escala } \\
\hline 0 & Nenhuma folha com sintomas \\
\hline 10 & De $0,1 \%$ a $19,9 \%$ das folhas com sintomas \\
\hline 30 & De 20 a $29,9 \%$ das folhas com sintomas \\
\hline 40 & De 40 a $39,9 \%$ das folhas com sintomas \\
\hline 50 & De 50 a $59,9 \%$ das folhas com sintomas \\
\hline 60 & De 60 a $69,9 \%$ das folhas com sintomas \\
\hline 70 & De 70 a $79,9 \%$ das folhas com sintomas \\
\hline 80 & De 80 a $89,9 \%$ das folhas com sintomas \\
\hline 90 & De 90 a $99,9 \%$ das folhas com sintomas \\
\hline 100 & Todas as folhas com sintomas \\
\hline
\end{tabular}




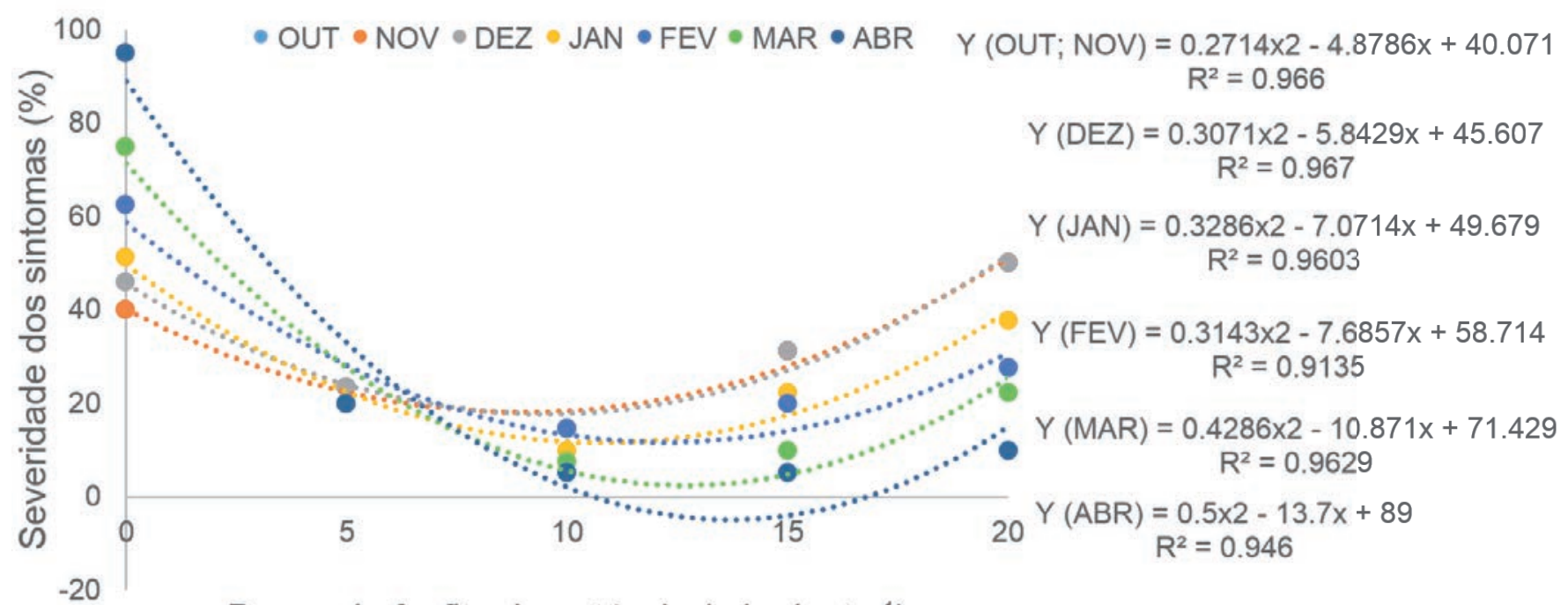

Doses de fosfito de potássio ( $\mathrm{mL}$ planta-1)

Figura 1. Valores médios de severidade dos sintomas do Mal do Panamá na banana "Prata anã", tratadas com fosfito de potássio, em diferentes épocas de avaliação

Figure 1. Average values for the symptoms severity of Panama disease in the "Prata anã" banana, treated with potassium phosphite, at different times of evaluation

proporcionaram uma melhor condição fitossanitária das plantas (Figura 1). Em complemento, calculando-se os pontos de máxima dose de fosfito, constatouse que entre os meses de avaliação, as concentrações variando entre $8,99 \mathrm{~mL}$ planta-1 ${ }^{-1}$, para os meses de outubro e novembro e $13,70 \mathrm{~mL}^{\text {planta-1 }}{ }^{-1}$ para o mês de abril, foram as que proporcionaram maior controle da severidade do Mal do panamá.

Para a produtividade, foi observada a perda total de frutos no tratamento controle, sem aplicação do fosfito de potássio (Figura 2), demonstrando a severidade passível de ser atingida e a importância do manejo desta doença para a cultura da bananeira.

Nos demais tratamentos foi verificada produtividade média de $16,00 \mathrm{Kg}$ planta $^{-1}$, observando o aumento desta variável até o ponto de máxima dose calculada de $14,43 \mathrm{~mL}$ planta ${ }^{-1}$, para a qual foi constatada produtividade de $18,97 \mathrm{Kg}$ planta- $^{-1}$ (Figura 2). A partir desse ponto, foi observada tendência de queda de produtividade à medida que se aumentaram as doses de fosfito.

Em complemento às características supracitadas quanto à atuação dos fosfitos, verifica-se também que estes elevam a resposta dos vegetais em virtude da ação de organismos patogênicos, resultando em ações como o aumento

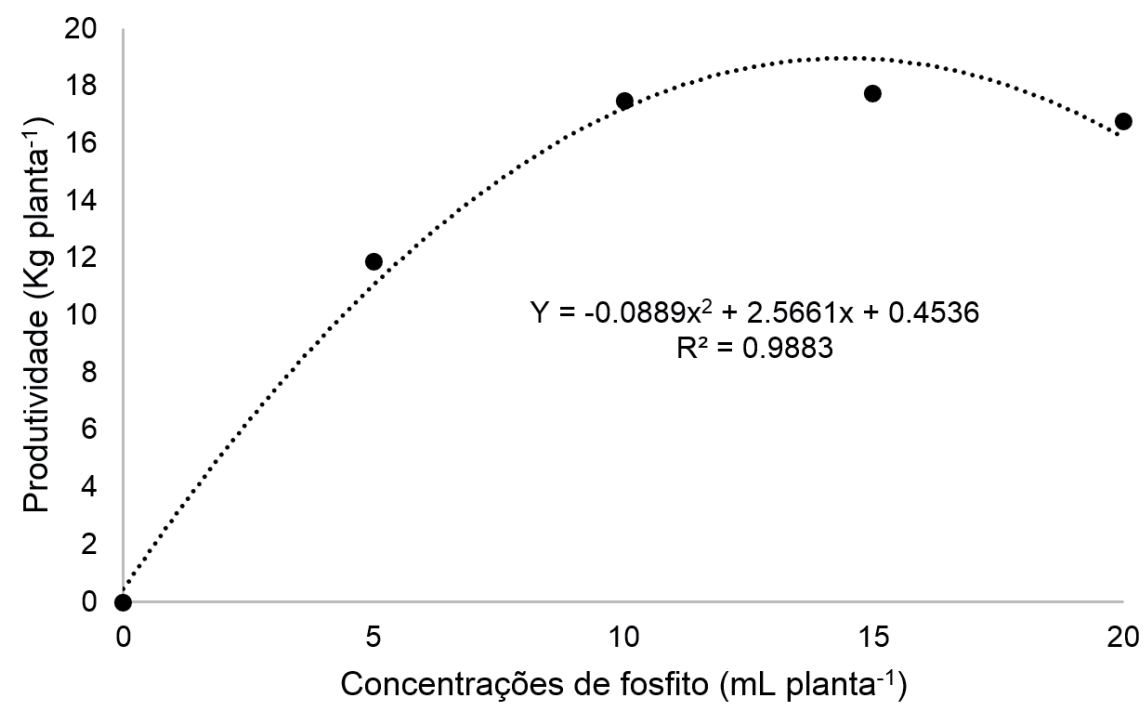

Figura 2. Valores médios de produtividade da banana cv. "Prata anã", tratadas com fosfito de potássio

Figure 2. Average values of productivity of banana cv. "Prata anã", treated with potassium phosphite

da concentração de fitoalexinas, ativação do metabolismo secundário, lignificação das paredes celulares, morte celular e interação antagônica direta ao patógeno (DANIEL \& GUEST, 2005).

Com base no disposto, conclui-se que doses de fosfito de potássio situadas entre 10 e $15 \mathrm{ml} \mathrm{planta}^{-1}$ reduzem significativamente a severidade dos sintomas do Mal do panamá em bananeiras e a dose de $14,43 \mathrm{~mL}$ planta $^{-1}$ é recomendada para o incremento da produti- vidade em área contaminada.

\section{Referências}

ARAÚJO, W.J.S.; DE ASSIS, T.C.; DE ANDRADE, D.E.; GURGEL, L.M.S.; DA ROSA, R.C.T. Manejo do mal do panamá da bananeira utilizando Trichoderma sp. E óleos essenciais de Lippia sidoides. Anais da Academia Pernambucana de Ciência Agronômica, Recife, v. 15, n. 2, p. 73-90, 2018. Disponível em: http:// ead.codai.ufrpe.br/index.php/apca/article/ / 
view/2307. Acesso em 23 julho 2020.

CARMONA, M.; SAUTUA; F. Os fosfitos no manejo de doenças nas culturas extensivas. Revista Plantio Direto, Passo Fundo, p. 21. nov/dez 2011. Disponível em: https:// wp.ufpel.edu.br/consagro/files/2012/02/ Os-fosfitos-no-manejo-de-doen\%C3\%A7asnas-culturas-extensivas.pdf. Acesso em: 23 julho 2020.

DANIEL, R.; GUEST, D. Defense responses induced by potassium phosphonate in Phytophthora palmivora-challenged Arabidopsis thaliana. Physiological and Molecular Plant Pathology, Amsterdam, v.67, p.194201, 2005. DOI: https://doi.org/10.1016/j. pmpp.2006.01.003.

FAO. Food and Agriculture Organization of the United States. Crops (Production). 2020. Disponível em: http://faostat.fao.org/. Acesso em 26 agosto 2020.

FERREIRA, D.F. Sisvar: a Guide for its Bootstrap procedures in multiple comparisons. Ciência e Agrotecnologia, v. 38, n. 2, p. 109112, 2014. DOI: https://doi.org/10.1590/ S1413-70542014000200001
GENTILE, S.; VALENTINO, D.; TAMIETTI, G. Control of ink disease by trunk injection of potassium phosphite. Journal of Plant Pathology, Amsterdam, v. 91, n. 3, p. 565-571, 2009. Disponível em: https://www.jstor.org/ stable/41998673. Acesso em: 23 julho 2020.

MACHINANDIARENA, M.F.; LOBATO, M.C.; FELDMAN, M.L.; DALEO, G.R.; ANDREU, A.B. Potassium phosphite primes defense responses in potato against Phytophthora infestans. Journal of Plant Physiology, Amsterdam, v. 169, n. 14 , p. 1417-1424, 2012. DOI: https://doi.org/10.1016/j. jplph.2012.05.005.

PERUCH, L.A.M.; BRUNA, E.D. Relação entre doses de calda bordalesa e de fosfito potássio na intensidade do míldio e na produtividade da videira cv. 'Goethe'. Ciência Rural, Santa Maria, v. 38, n.9, dez, 2008. DOI: https://doi. org/10.1590/S0103-84782008000900001.

REUVENI, M. Post-infection applications of $\mathrm{K}_{3} \mathrm{PO}_{3}$, phosphorous acid and imethomorph inhibit development of downy mildew caused by Plasmopara viticola on grapevines. Journal of Small Fruit \& Viticulture, Baton Rouge, v. 5, n. 22, p. 27-38, 1997. DOI:
https://doi.org/10.1300/J065v05n02_03.

ROCHA SOBRINHO, G.G.; RODRIGUE, G.B.; SANTOS, A.; JUNIOR, J.; NOVAES, Q.S.D. Efeito de fosfito de potássio no crescimento e na densidade micelial do Fusarium solani do maracujazeiro. Summa Phytopathologica, Botucatu, v. 42, n. 2, p. 180-182, 2016. DOI: https://doi.org/10.1590/0100-5405/2139.

RODRIGUES FILHO, V.A.; DONATO, S.L.R.; SILVA, T.S.; AMORIM, E.P. Características agronômicas e ocorrência de mal do panamá em bananeiras tipo Pacovan. Revista Brasileira de Fruticultura, Jaboticabal, v. 36, n. 2, p. 515-519, 2014. Disponível em: https://www.alice.cnptia.embrapa.br/handle/ doc/998517. Acesso em: 23 julho 2020.

SILVA, S.O.; MATOS, A.; CORDEIRO, Z.J.M.; LIMA, M.J.C.; AMORIM, E.P. Avaliação de genótipos tetraploides de bananeira cultivados em área infestada pelo agente causal do mal do panamá, Revista Brasileira de Fruticultura, Jaboticabal, v. 33, p. 125-132, 2011. DOI: https://doi.org/10.1590/S010029452011005000029 .

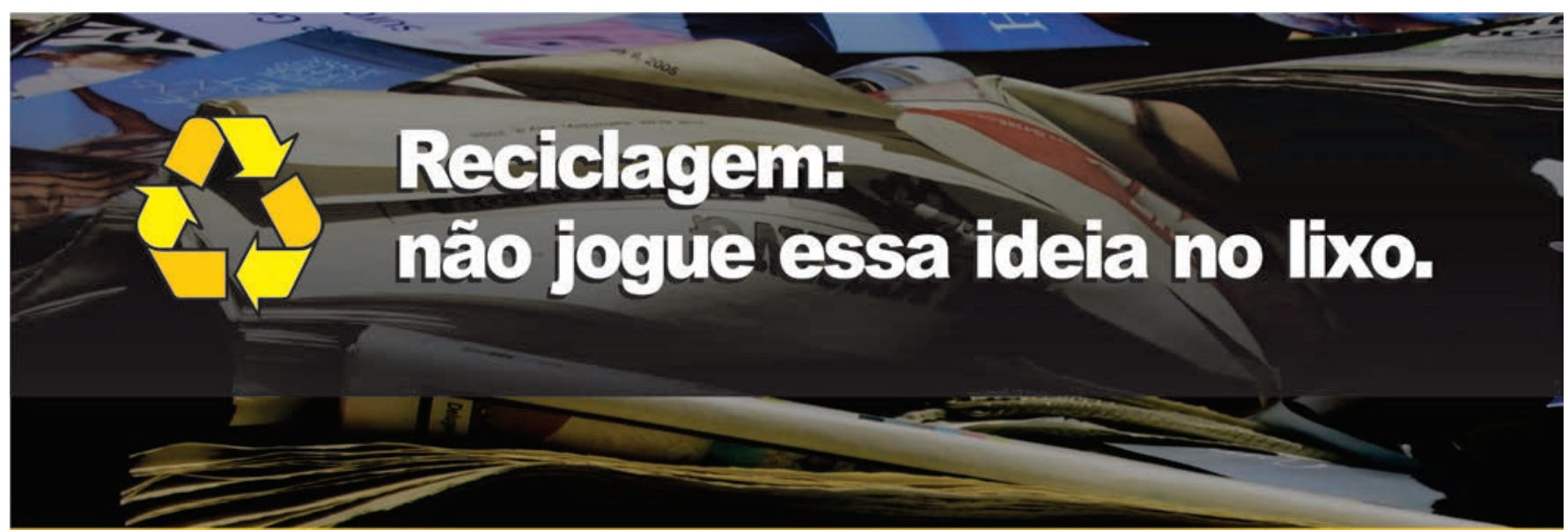

Cada 50 quilos de papel reciclado evitam o corte de uma árvore. $\mathrm{Na}$ natureza, o papel leva de 1 a 3 meses para se decompor

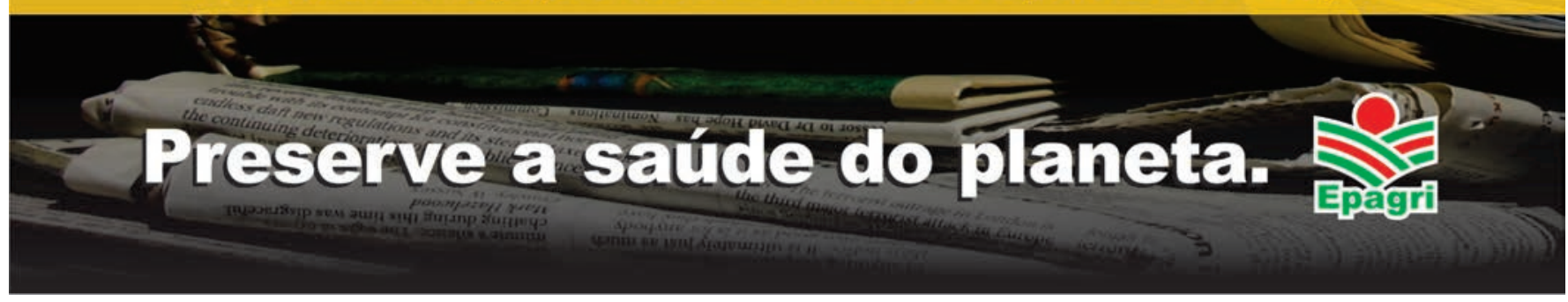

